\title{
\begin{tabular}{l|l} 
jurnal jurnal Kependidikan Dasar \\
ibriez
\end{tabular}
}

Volume 6

Nomor 2

Tahun 2021

\section{PENDIDIKAN INTEGRITAS \\ DALAM WACAN BOCAH MAJALAH PANJEBAR SEMANGAT: KAJIAN STRUKTURAL TEKS SASTRA ANAK BERBAHASA JAWA}

\author{
Latif Nur Hasan1, Udjang Pairin² \\ 1,2Universitas Negeri Surabaya \\ Surel:latifhasan@unesa.ac.id
}

\begin{abstract}
Abstrak
Sastra anak sangat penting dalam proses pewarisan sastra, utamanya sastra Jawa karena penggunaan bahasa Jawa pada anak mulai luntur. Tidak hanya sebagai warisan sastra, dalam karya sastra anak terkandung pendidikan-pendidikan karakter yang dibutuhkan untuk perkembangan anak. Salah satunya adalah pendidikan karakter integritas yang banyak ditemukan dalam teks-teks sastra anak "wacan bocah majalah Panjebar Semangat". Penelitian ini bertujuan untuk mengungkap nilai pendididikan integritas yang terkandung dalam wacan bocah tersebut. Pendekatan yang digunakan dalam penelitian ini adalah pendekatan terhadap teks yaitu hanya memfokuskan pada hasil karya (teks) bacaan sastra anak. Objek kajian penelitian ini adalah karya sastra anak berbahasa Jawa yang dimuat dalam Majalah Berbahasa Jawa Panjebar Semangat tahun 2020. Hasil analisis karakter integritas tersebut ditemukan ada empat jenis pendidikan karakter integritas, yaitu; 1) kejujuran, 2) keteladanan, 3) kesantunan, dan 4) cinta pada kebenaran. Keempat pendidikan karakter tersebut digambarkan baik secara implisit maupun eksplisit dalam wacan bocah.
\end{abstract}

Kata Kunci: teks sastra anak, bahasa Jawa, pendidikan karakter, integritas

\begin{abstract}
Children's literature is very important in the process of literary inheritance, especially Javanese literature because the use of Javanese language in children is starting to fade. Not only as a literary heritage, in children's literary works contained character education needed for child development. One of them is integrity character education which is found in many children's literary texts "Discussions for Boys in Panjebar Spirit magazine". This study aims to reveal the value of integrity education contained in the boy's discourse. The approach used in this study is an approach to the text that only focuses on the work (text) of children's literature reading. The object of this research study is a Javanese children's literary work published in the Java language magazine Panjebar Spirit in 2020. The results of the analysis of the character of integrity found that there are four types of integrity character education, namely; 1) honesty, 2) exemplary, 3) politeness, and 4) love of truth. The four character educations are described either implicitly or explicitly in the discourse of children.
\end{abstract}

Keywords: children's literary text, Javanese language, character education, integrity 


\section{A. PENDAHULUAN}

Warisan sastra pada anak-anak perlu dilakukan supaya eksistensi sastra tetap ada dalam jangka waktu lama. Salah satu cara untuk tetap mewariskan karya sastra adalah melalui adanya karya-karya sastra anak. Selain sebagai upaya pewarisan sastra, melalui karya sastra anak dapat memberikan pengalaman baru serta penanaman karakter-karakter baik kepada anak-anak sebagai pembacanya.

Sastra anak merupakan hasil karya cipta bermuatan etik, estetik, dan saintik baik menggunakan media bahasa baik secara lisan atau tulis yang berisikan tentang segala hal tentang dunia anak-anak. Menurut Sarumpaet1, sastra anak merupakan sastra terbaik yang dibaca anak dengan karakteristik yang beragam, tema, dan format. Sastra anak tersebut ditulis berdasarkan sudut pandang anak yang mencerminkan perasaan dan pengalaman dan dunia anak-anak. Ada beberapa hal yang terkait dengan sastra anak yaitu; 1) Sastra anak adalah sastra yang memang sengaja ditujukan untuk anak-anak seperti Bobo, Mentari dll., 2) Sastra anak berisi cerita yang menggambarkan pengalaman, pemahaman, dan perasaan anak, 3) Sastra anak adalah sastra yang ditulis oleh anak-anak, 4) Sastra anak adalah sastra yang berisi nilai-nilai moral atau pendidikan yang bermanfaat untuk anak.

Berdasarkan keempat uraian tersebut dapat ditarik kesimpulan bahwa sastra anak adalah karya yang imajinatif melalui media bahasa yang berisi pengalaman, perasaan, dan pikiran anak yang khusus ditujukan bagi anak-anak, ditulis oleh pengarang anak-anak maupun pengarang dewasa. Rumidjan2 menyatakan, topik sastra anak mencakup semua yang dekat dengan dunia anak-anak, kehidupan manusia, binatang, tumbuhan yang mengandung nilai-nilai pendidikan, moral, agama, dan nilai positif lainnya.

Rumidjan3 menjelaskan mengenai karakteristik sastra anak bisa dilihat dari dua segi, yaitu dari kebahasaan dan kesastraan. Segi kebahasaan dilihat dari struktur kalimat, pilihan kata, dan gaya bahasa (majas). Struktur kalimat yang digunakan masih sederhana, berupa kalimat tunggal, kalimat berita, kalimat tanya, atau kalimat perintah sederhana. Pilihan kata dalam sastra anak menggunakan kata-kata yang sudah dikenal oleh anak-anak. Gaya bahasa masih sedikit karena lebih menggunakan kata-kata konkret.

Segi kesastraan memiliki karakteristik dalam hal alur cerita, tokoh, dan tema. Alur cerita disusun secara kronologis dengan hubungan sebab-akibat. Tokoh cerita berupa manusia, binatang, atau tanaman. Watak tokoh dalam cerita jelas baik dan jahat begitu saja. Tema dalam sastra anak memiliki tema tunggal.

Genre sastra anak dapat digolongkan seperti genre sastra orang dewasa. Menurut Winarni ${ }^{4}$, sastra anak dapat digolongkan menjadi tiga macam yakni puisi, prosa, dan drama. Pembedanya adalah muatan dan untuk siapa karya tersebut dibuat.

\footnotetext{
${ }^{1}$ Riris K. Toha Sarumpaet, Pedoman Penelitian Sastra Anak, Yayasan Pustaka Obor Indonesia, 2010.

2 Rumidjan, Dasar Keilmuan dan Pembelajaran Sastra Anak SD (FIP UM, 2013).

${ }^{3}$ Rumidjan.

${ }^{4}$ Retno Winarni, Kajian Sastra Anak, Yogyakarta: Graha Ilmu, 2014.
} 
Karya sastra anak dibuat dalam berbagai macam bahasa pengantar, salah satunya adalah menggunakan bahasa Jawa. Teks sastra anak berbahasa Jawa yang saat ini masih eksis yaitu Wacan Bocah yang menjadi salah satu rubrik dalam Majalah Panjebar Semangat. Majalah Panjebar Semangat merupakan majalah berbahasa Jawa yang sampai saat ini masih eksis untuk melestarikan bahasa dan sastra Jawa.

Setiap edisi terbitan Majalah Panjebar Semangat yaitu 4-5 edisi dalam satu bulan, tidak pernah terlewatkan rubrik wacan bocah yang sangat menarik untuk dikaji. Berdasarkan hasil pembacaan secara intensif oleh peneliti, wacan bocah yang diterbitkan pada majalah Panjebar Semangat sangat sarat akan pendidikan karakter untuk anak-anak terutama pada karakter integritas. Oleh karena itu peneliti tertarik untuk mengkaji wacan bocah tersebut utamanya mengenai nilai Pendidikan Karakter Integritas yang terkandung di dalamnya.

Kata karakter berasal dari bahasa Yunani yang berarti "to mark" (menandai) dan memfokuskan, bagaimana mengaplikasikan nilai kebaikan dalam bentuk tindakan atau tingkah laku.5 Seseorang yang berperilaku tidak jujur, kejam, atau rakus dikatakan sebagai orang yang berkarakter jelek, sementara orang yang yang berperilaku jujur, suka menolong dikatakan sebagai orang yang berkarakter. Seseorang bisa disebut orang yang berkarakter apabila perilakunya sesuai dengan kaidah moral. Menurut KBBI (2008) karakter merupakan sifat-sifat kejiwaan, akhlak atau budi pekerti yang yang membedakan seseorang dengan yang lain. Karakter adalah nilai-nilai yang unik-baik yang terpatri dalam diri dan terejawantahkan dalam perilaku. Menurut Samani6, secara universal berbagai karakter dirumuskan sebagai nilai hidup bersama berdasarkan atas pilar, kedamaian (peace), menghargai (respect), kerjasama (cooperation), kebebasan (freedom), kebahagiaan (happiness), kejujuran (honesty), kerendahan hati (humility), kasih sayang (love), tanggung jawab (responsibility), kesederhanaan (simplicity), toleransi (tolerance), dan persatuan (unity).

Tulisan ini merupakan penelitian yang baru dan orisinil. Sebagai pembanding, berikut dipaparkan beberapa penelitian terdahulu yang memiliki kesamaan dan perbedaan. Penelitian pertama yang ditulis oleh Sugiarti7 dengan judul "Kajian Sastra Anak "Kecil-Kecil Punya Karya The Evergreen "Karya Nisrina Hanifah Dalam Perspektif Pendidikan Karakter" hasilnya (1) mendeskripsikan aspek kebahasaan sastra anak yang terefleksi melalui struktur kalimat, diksi, gaya bahasa (2) mendeskripsikan aspek kesastraan sastra anak yang terefleksi melalui alur cerita, karakter, serta tema, (3) menjelaskan temuan apa yang dapat diungkapkan terkait dengan aspek kebahasaan dan kesastraan pada sastra anak dalam perspektif pendidikan karakter. Perbedaan dengan penelitian yang dilakukan ini adalah

\footnotetext{
${ }^{5}$ Zubaedi, Desain Pendidikan Karakter, Jakarta: Kencana Prenada Media Group, 2013.

${ }^{6}$ Muchlas Samani dan Hariyanto, Pendidikan Karakter (Bandung: Rosdakarya, 2011).

7 Sugiarti, "Kajian Sastra Anak " Kecil-Kecil Punya Karya the Evergreen " Karya Nisrina Hanifah dalam Perspektif Pendidikan Karakter,” Jurnal Humanity 8, no. 2 (2013): 94-105, http://ejournal.umm.ac.id/index.php/humanity/article/view/2103.
} 
difokuskan pada pendidikan karakter untuk anak-anak, dan karya sastra yang dikaji adalah karya sastra berbahasa Jawa. Ada kesamaan yaitu mengenai penjabaran karakter dalam karya sastra anak.

Penelitian kedua yang ditulis oleh Neina8 yaitu dengan judul "Dongeng Abad 21: Modernisasi Sastra Anak Berbasis Psikologi Perkembangan", hasil penelitiannya (1) deskripsi hasil analisis struktur cerita anak, (2) deskripsi hasil analisis keterkaitan tema dan jalan cerita dalam dongeng, dan (3) skor kecenderungan analisis kebutuhan psikologi, sosial, dan moral pada anak usia dini. Penelitian tersebut merupakan penelitian pengembangan, sehingga berbeda dengan penelitian ini. Persamaannya adalah adanya kajian struktural dalam karya sastra anak.

\section{B. METODE PENELITIAN}

Menurut Galda, $\mathrm{dkk}^{9}$ dalam penelitian atau telaah sastra anak setidaknya dapat dilakukan dengan tiga pendekatan yaitu; 1) penelaahan atau penelitian terhadap teks, 2) penelaahan atau penelitianntasa pembaca (kanak-kanak), dan penelaahan atau penelitian atas keterlibatan anak dengan karya yang dibaca. Pendekatan yang digunakan dalam penelitian ini adalah pendekatan yang pertama yaitu penelitian terhadap teks. Pemilihan pendekatan ini hanya untuk memfokuskan pada hasil karya (teks) bacaan sastra anak.

Objek kajian penelitian ini adalah karya sastra anak berbahasa Jawa yang dimuat dalam Majalah Berbahasa Jawa Panjebar Semangat. Karya sastra ini terbatas hanya pada tahun 2020. Jumlah Karya sastra anak yang dikaji adalah 48 karya sastra pada masingmasing edisi terbitan.

Dalam menghimpun data-data untuk penelitian, baik itu data-data utama maupun data-data tambahan, dibutuhkan akses kepada berbagai sumber. Teknik pengumpulan data yang akan dilakukan selama penelitian adalah studi literatur dari beberapa sumber buku, hasil penelitian, dan makalah-makalah yang sudah diseminarkan, serta merefleksikan berbagai jurnal ilmiah terkait. Kajian literatur tersebut dibatasi pada bacaan anak dan halhal yang membahas tentang sastra anak.

\section{HASIL DAN PEMBAHASAN}

Penanaman pendidikan karakter pada anak melalui karya sastra berbahasa Jawa Majalah panjebar semangat. Terdapat empat macam pendidikan karakter integritas yang ditemukan dalam cerita yaitu; 1) kejujuran, 2) keteladanan, 3) kesantunan, dan 4) cinta pada kebenaran. Keempat penanman karakter tersebut dijabarkan lebih lanjut sebagai beikut:

${ }^{8}$ Qurrota Ayu Neina, "Dongeng Abad 21: Modernisasi Sastra Anak Berbasis Psikologi Perkembangan," Jurnal Sastra Indonesia 7, no. 3 (2019): 202-11, https://doi.org/10.15294/jsi.v7i3.29846.

${ }^{9}$ B. E Galda, Lee, Ash, G. E., \& Cullinan, "Research on Children's Literature," 2001. 


\section{Kejujuran}

Nilai kejujuran dapat dimaknai mengakui, berbicara atau memberikan informasi sesuai dengan kenyataan yang ada. Kejujuran dalam wacan bocah nampak pada wacan bocah berjudul "Ayo Nyepedhah", ditunjukkan oleh siswa yang menjawab dengan jujur apa yang ditanyakan oleh Bu Rahayu.

“... Ngendikane Bu Rahayu mancing-mancing. Lah ndilalah sing dipancing gampang wae kecanthol. Siji mbaka siji bocah-bocah kuwi padha ngandhakake apa sing dingerteni ngenani hubungane Siska lan Joni." (Panjebar Semangat No.15-11 April 2020, Kaca 46).

Terjemahan :

“... Perkataannya Bu Rahayu memancing-mancing. Lah ternyata yang dipancing mudah untuk terpancing. Satu persatu anak-anak tersebut mengatakan apa yang dimengerti mengenai hubungan antara Siska dan Joni." (Panjebar Semangat No.15-11 April 2020, Halaman 46).

Cuplikan tersebut secara tidak langsung menunjukkan bahwa anak-anak atau siswa di kelas tersebut mengatakan apa yang mereka ketahui dengan jujur. Seluruh siswa mengatakan dengan sebenarnya apa yang telah terjadi. Hal ini dapat dijadikan contoh untuk anak-anak bahwa seseorang harus bersikap jujur.

Nilai pendidikan karakter kejujuran juga terkandung dalam wacan bocah "Bola-Bali Jaga" digambarkan oleh seorang anak yang bernama Tatang. Tokoh Tatang ini mempunyai watak jujur. Kejujuran Tatang dengan menceritakan apa yang sebenarnya terjadi kepada teman-temannya membawanya ke dalam suatu masalah, namun Tatang tidak mempedulikan hal itu, ia tetap saja berkata jujur.

"Tang, kowe saka ngendi, awakmu kan sing jaga kok malah ditinggal lunga" pitakone kancane marang Tatang.

"Tang, kamu dari mana saja, kamu kan yang jaga kok malah ditinggal pergi" tanya temannya kepada Tatang.

Terjemahan :

“Iya, sepurane wetengku mau mules, dadi tak tinggal” wangsulane Tatang kanthi mringis.

"Iya, maaf perutku tadi mulas, maka aku tinggal” jawab Tatang dengan senyuman tipis.

(Panjebar Semangat, 10 Januari 2020, ed 3: 45)

Dari kutipan percakapan di atas, dapat diketahui bahwa Tatang berkata jujur ketika ia ditanya perihal alasannya meninggalkan permainan saat ia berjaga. Diceritakan bahwa ketika permainan petak umpet berlangsung, ia merasa perutnya mulas sehingga ia memutuskan untuk pulang sebentar. Dengan pulangnya Tatang, teman-temannya keluar dari persembunyian dan bingung mengapa Tatang tidak ada. Ketika Tatang kembali salah satu temannya menanyakan alasan Tatang pergi. 
Sikap jujur yang dilakukan Tatang di atas dapat mencotohkan suatu nilai pendidikan karakter yang baik bagi anak-anak. Nilai pendidikan karakter kejujuran tersebut dapat membuat anak-anak yang membacanya ikut pesan tersebut dan menerapkannya dalam diri pribadinya. Pendidikan karakter jujur juga tergambar dalam kutipan berikut:

"Sasa melas kalih ibu, mangke pendamelane ibu tansaya kathah ketambahan ngingu kucing."

"Lho, sing arep ngopeni kan Sasa dudu ibu,"

"Hehe kadosipun Sasa mboten saged ngopeni piyambak, mesthi ngrepoti ibu." Sumaure Sasa karo mesam mesem

Terjemahan :

"Sasa kasihan dengan ibu, anti pekerjaan ibu semakin banyak ketambahan memelihara kucing."

"Lho yang akan merawat kan Sasa bukan ubi."

“Hehe sepertinya Sasa tidak akan bisa merawatnya sendiri, pasti akan merepotkan ibu." Jawab Sasa dengan senyam senyum

Pendidikan karakter kejujuran Sasa terlihat jelas pada kutipan di atas. Sasa berkata dengan jujur kepada ibunya bahwa dia tidak akan bisa merawat kucing sendirian. Dia juga jujur merasa kasihan jika pada akhirnya dia merepotkan ibunya mengurus kucing. Kejujuran ini tulus dikatakan oleh Sasa tanpa rasa egois tetap mementingkan keinginannya memelihara kucing. Dia lebih baik memilih jujur sejak awal jika tidak sanggup mengurus kucing sendirian, daripada akhirnya dia hanya menyusahkan ibunya seperti temanya Kara.

Nilai kejujuran juga terdapat dalam cerita "Kancil Pilek", seperti pada kutipan berikut:

"piye kebo? Kedhatonku iku piye kahanane?" pitakone macan

"Matur jujur lho nggih?"

"Iya."

"wah... kedhaton panjenengan menika ambetipun kok pesing tur badheg menika persis kandhang kewan."

"piye?"

“ambetipun mboten ngiyati. Kula meh mutah kalawau!"

Terjemahan :

“bagaimana kebo? Rumahku ini bagaimana keadaannya?" pertanyaan Macan

"bicara jujur lho ya?"

"Iya."

"Wah... rumahmu ini baunya pesing dan tidak enak ini sama dengan kandhang hewan"

"bagaimana?" 
"baunya tidak kuat, saya tadi hamper mau muntah!"

Dalam kutipan tersebut dijelaskan bahwasannya macan bertanya kepada kebo tentang keadaan rumahnya. Kebo disuruh menjawab jujur oleh Macan agar mengatakan yang sebenarnya. Kebo jujur dengan apa yang dirasakan dan diciumnya bau tidak enak dalam rumah Macan tersebut. Kebo mengatakan kalau rumah Macan tersebut bau kencing dan tidak enak. Sampai-sampai Kebo mau muntah di dalam rumah Macan tersebut karena tidak kuat dengan baunya. Dalam kutipan data tersebut memberikan gambaran pendidikan karakter kejujuran untuk disalurkan ke anak-anak lewat cerita anak tersebut, walaupun dalam keadaan yang membahayakan.

Ketika hewan-hewan yang lain masih berkumpul dan disuruh bergantian untuk melihat keadaan rumah Macan. Hewan-hewan menunggu dan menanti giliran untuk melihat rumah Macan dan harus menjawab pertanyaan Macan satu per satu. Hal itu dapat dilihat pada kutipan data sebagai berikut:

Kewan-kewan liya sing mlebu ing kedhaton lan kandha kanthi jujur ngalami nasib sing padha. Bantheng, Menjangan, Kidang, truwelu sing kandha jare kandhange pesing diperjaya siji mbaka siji.

Terjemahan :

Hewan-hewan yang lain yang masuk rumahnya dan berbicara dengan jujur mengalami nasib yang sama. Banthen, menjangan, kidang, truwelu, yang berbicara kalau rumahnya pesing dihabisi satu per satu.

Pada kutipan data tersebut dijelaskan bahwa hewan-hewan tersebut mempunyai nasib yang sama dengan Kebo. Meskipun hewan-hewan tersebut sudah menanti untuk bergiliran masuk kedalam rumanya Macan. Hewan-hewan juga sudah memberikan kejujuran kepada Macan. Kalau tempat tinggalnya tersebut memang baunya pesing dan tidak enak. Akan tetapi Macan tetap bertindak untuk menghabisi hewan-hewan yang sudah berkata jujur tersebut.

Giliran Kethek untuk memasuki tempat tinggal macan yang memiliki bau tidak enak dan kurang nyaman jika ada di dalam rumah tersebut. akan tetapi kethek tidak menjawab pertanyaan jujur dari si Macan. Ketidakjujuran tersebut terdapat pada kutipan data yaitu:

"piye kethek? Kedhatonku iki piye ambune?" pitakone macan

“Wah... papan patunggon panjenengan menika sae saestu. Papan kok ambetipun wangi kados sinebaran minyak kesturi. Papnipun ugi tinata asri. Menika tuhu papan sae tur endah. Cocok kagem papanipun raja," wanguslane kethek.

Terjemahan :

“bagaimana kethek? Rumahku ini bagaimana baunya?" pertanyaan dari Macan

"wah... tempatmu ini bagus banget. Tempat kok baunya wangi seperti bau minyak kesturi. Tempat ini juga tertata rapi. Itu tempat bagus dan indah. Cocok buat tempatnya Raja." Jawabannya kethek. 
Pada kutipan data di atas menjelaskan bahwa si kethek tidak berkata jujur, karena kethek tidak ingin nasibnya sama dengan hewan-hewan yang lain. Maka dari itu si kethek mengatakan bahwa tempat tinggal Macan itu bagus banget. Tempatnya baunya wangi seperti minyak kasturi. Tempatnya juga tertata rapi. Tempat tersebut cocok untuk ditempati raja karena bagus dan indah. Karena yang diucapkan si kethek memang kebalikan dari sebenarnya Macan mengetahui akan hal itu. Akan tetapi nasib kethek sama seperti nasib hewan-hewan yang lainnya.

Dalam kutipan data tersebut memberikan gambaran pendidikan karakter kejujuran untuk disalurkan ke anak-anak lewat cerita anak tersebut. karena kejujuran merupakan salah satu sikap yang harus dimiliki oleh seseorang. Akan tetapi banyak sekali orang-orang yang tidak jujur untuk mendapatkan apa yang di inginkan. Maka harus di ajarkan kejujuran tersebut sejak dini untuk anak-anak.

Nilai kejujuran yang ada pada cerita "Joni Ora Mlebu Sekolah" adalah sebagai berikut:

"Kula dolanan PS teng griyane Budi,Bu"wangsulane Joni alon.

"Sapa kuwi Budi? Kelas pira?"

"Kelas enem Bu, nanging benten ekolahan."

"Budi ya ora mlebu? Banjur sing marai mbolos sapa?"

"Mboten Bu, Budi ingkang ngajak, amargi nembe ditumbasake PS enggal"kandhane Joni blaka suta.

Terjemahan :

"Saya bermain PS di rumah Budi, Bu" Jawab Joni dengan pelan.

"Siapa Budi itu? Kelas berapa?"

"Kelas enam Bu, tetapi beda sekolah"

"Budi ya tidak masuk? Lalu siapa yang mengajak untuk membolo?"

“Tidak Bu, Budi yang mengajak, karena baru saja dia dibelikan PS baru” kata Joni dengan penuh penjelasan.

Kutipan dialog di atas menunjukkan bahwa meskipun Joni sudah melakukan kesalahan besar, ia mencoba untuk berkata dengan penuh kejujuran apa yang telah ia lakukan. Ia berkata bahwa alasan ia tidak masuk sekolah adalah bermain PS di ruma Budi, teman kelas 6 yang berbeda sekolah dengannya. Bu Jar akhirnya lega mendengar apa yang sudah dikatakan Joni. Hal ini menjadikan Bu Jar senang, dibuktikan melalui kutipan berikut ini :

"Bu Jar marem dene Joni wis gelem mangsuli. Senajan tumindake kleru nanging ora gawe alasan anggone mangsuli. Tegese Joni blaka apa anane. Bu Jar nuturi supaya Joni ora mbaleni anggone mbolos maneh."

Terjemahan : 
"Bu Jar tersenyum karena Joni sudah mau menjawab pertanyaannya. Meskipun apa yang telah dilakukannya itu salah, namun tidak menjadi alasan untu menjawab pertanyaan. Makudnya adalah Joni telah berani berkata dengan jujur apa adanya. Bu Jar menasihati supaya Joni tidak membolos sekolah lagi."

Setelah kita ketahui secara bersama, akhirnya Joni memang memiliki sifat yang jujur, meskipun dia melakukan kesalahan tidak menghalanginya untuk tetap berbuat baik. Seperti itulah nilai kejujuran yang ada pada cerita "Joni Ora Mlebu Sekolah".

Cerita anak identik dengan suasana dan jiwa khas anak-anak. Tokoh-tokohnya juga banyak diperankan oleh anak-anak. Begitu pula dengan cerita anak yang berjudul Golek Jamur Damen ini. Tokoh-tokoh anak kecil identik dengan kepolosannya, yang salah satunya adalah kejujuran. Sifat jujur dimiliki okeh tokoh bernama Ayuk yang semangat pergi ke sawah untuk mencari jamur di tumpukan jerami padi. Bentuk kejujuran yang dimiliki Ayuk adalah sebagai berikut:

"Bapak dhawuh yen ana ing tumpukan damen pinggir sawah sing wis bosok bakal thukul jamure. Ning kanyatane, aku, eva lann Rini wus pirang-pirang tumpukan damen dak goleki babar pisan ora ana jamure. Kuwi rak jenenge ngapusi ta Mbah?" Swarane Ayuk sengol merga mangkel.

Terjemahan :

"Bapak berkata jika di tumpukan jerami padi di pinggir sawah yang sudah membusuk akan tumbuh jamur. Tapi nyatanya, aku, Eva dan Rini sudah banyak tumpukan jerami padi yang kami cari tak satupun ada jamurnya. Itu kan namanya berbohong, Mbah?" Suara Ayuk dengan kesal.

Kejujuran yang dimiliki Ayuk adalah berkata apa adanya kepada sang nenek tentang apa yang dia rasakan. Sang ayah berkata padanaya bahwa pada tumpukan jerami padi yang sudah membusuk akan tumbuh jamur Akan tetapi setelah dicari, Ayuk tidak menemukan satu jamur sekalipun. Hal tersebut disampaikan kepada neneknya dengan penuh perasaan kesal.

Kejujuran adalah sikap yang lurus hati, menyatakan yang sebenar-benarnya tidak berbohong atau berkata hal-hal yang menyalahi apa yang terjadi sesuai dengan fakta. Jujur juga dapat dimaknai tidak curang, melakukan sesuatu sesuai dengan aturan yang berlaku dan lain sebagainya. Seperti kutipan dibawah ini.

Mano banjur matur marang ibune karo praupan sing sajak susah. "Wonten gelandhangan sakit mergi nedha ayam goreng ingkang kula bucal teng tong sampah, Bu"

Terjemahan :

Kemudian Mano mengatakan kepada ibunya dengan wajah yang sedih. "Ada gelandangan yang sakit karena memakan ayam goreng yang aku buang di tong sampah, Bu."

Dari kutipan tersebut, dapat diketahui bahwa Mano telah bersikap jujur. Ia menyatakan yang sebenar-benarnya terjadi, ia mengakui bahwa dirinya yang telah menyebabkan gelandangan itu sakit. Gelandangan tersebut perutnya menjadi sakit karena 
telah memakan ayam goreng yang dibuang Mano ke tempat sampah. Mano berkata apa adanya kepada ibunya, meskipun dengan wajah sedih dan takut. Mano telah menunjukkan sikap jujur.

Jujur merupakan salah satu perbuatan terpuji yang harus kita tanamkan dalam kehidupan sehari-hari. Perilaku jujur dapat diartikan sebagai perbuatan tidak berdusta ketika berbicara. Dalam kehidupan sehari-hari perilaku jujur harus kita tanamkan dalam diri kita, karena perlaku jujur merupan pondasi yang menentukan hubungan seseorang dengan orang lain. Dalam bacaan anak dengan judul "Wong Pepriman kan Jujur" ini mengisahkan tentang kejujuran seorang pengemis saat menemukan sebuah tas kulit milik saudagar kaya.

"Aku lagi kelangan tas kulit isi koin emas. Mula aku bakal menehi hadiah marang sapa wae kang nemokake tasku kuwi," bengoke saudagar sugih kuwi.

Terjemahan :

"Aku sedang kehilangan tas kulis yang isinya koin emas. Aku bakal member hadiah kepada siapapun yang menemukan tasku," teriak si saudagar kaya.

Kutipan tersebut menceritakan tentang saudagar kaya yang sedang kehilangan tasnya yang berisi koin emas. Si saudagar tersebut memberikan sebuah pengumuman kepada orang-orang dipasar. Dalam pengumuman tersebut dijelaskan oleh si saudagar tersebut bahwa siapapun yang menemukan tasnya akan mendapat hadiah darinya.

"Pranyata si sudagar kuwi wong kang licik lan serakah. Dheweke malah duwe karep pengin hapusi wong pepriman kuwi."

Terjemahan :

"Ternyata si saudagar tersebut merupakan orang yang licik dan serakah. Dia malah ingin menipu preman tersebut."

Pengumuman yang disampaikan oleh saudagar tersebut didengar oleh semua orang. Si pengemis juga turut mendengar perkataan si saudagar tersebut. Setelah pengumuman tersebut selesai, datanglah pengemis tersebut kepada saudagar kaya, berniat ingin memgembalikan tas saudagar tersebut. Tak lupa ia juga meminta imbalan atas apa yang telah dilakukannya. Namun tanpa diduga si saudagar kaya tersebut malah menipu pengemis tersebut dan menuduhnya telah mencuri uangnya. Dari kutipan tersebut dapat diketahui bahwa perilaku jujur tidak diterapkan oleh saudagar tersebut. Ia berbohong atas janji yang telah diucapkan sendiri. Perilaku tersebut bukanlah termasuk dalam perilaku terpuji.

\section{Keteladanan}

Salah satu nilai integritas adalah nilai keteladanan. Dalam wacan bocah berjudul "Ayo Nyepedhah" menunjukkan adanya nilai keteladanan yang ditunjukkan oleh bu Rahayu sebagai seorang guru.

"Senajan umume para siswane ora patiya nggape nanging panjenengane sajak ora duwe bosen apa maneh kapok." (Panjebar Semangat No.15-11 April 2020, Kaca 46). 
Terjemahan:

"Meskipun umumnya siswanya tidak begitu mendengarkan akan tetapi beliau (Bu Rahayu) sepertinya tidak punya rasa bosan apalagi rasa jera." (Panjebar Semangat No.15-11 April 2020, Halaman 46).

Dalam kutipan tersebut dapat diketahui bahwa bu Rahayu sebagai seorang guru memiliki nilai keteladanan yang patut dicontoh oleh siswanya. Keteladanan mempunyai kontribusi yang besar dalam mendidik karakter. Keteladanan yang diperlihatkan Bu Guru adalah pantang menyerah, dan tidak bosan walaupun siswanya kurang memperhatikan.

Keteladana dapat diartikan sebagai sikap yang mencerminakan hal-hal baik agar bisa dijadikan contoh untuk orang lain maupun kelompok tertentu. Dalam cerita anak ini keteladanan bisa ditemukan pada Koko yang sabar, Kiki yang toleransi, dan Cici yang meminta maaf. Koko sanagt sabar walaupun diejek oleh teman-temanya di kelas. Tetapi dia selalu ingat akan pesan ibunya untuk selalu bersabar.

"Pangandikane ibune sing ndadekake Koko tetep mesem senajan kerep oleh pangece saka kancane ing sekolahan."

Terjemahan :

"Pesan dari ibunya yang menjadikan Koko tetap tersenyum walaupun sering dihina oleh temanya di sekolahan."

Koko begitu sabar saat dihina oleh temanya terutama Cici si kelinci yang sering menghinanya. Dirinya selalu tersenyum dan tidak pernah membalas apa yang temantemanya lakukan padanya. Koko hanya bisa tersenyum dan kelak akan membuktikan kalua apa yang dituduhkan oleh teman-temanya merupakan hal yang salah. Selain itu keteladanan Koko dan Kiki juga sifat baik meraka yang berusaha menjaga harti temanya.

"Krungu ujare Cici sing sajak melas iki, sejatine Koko lan Kiki pengin ngguyu. Jalaran apa sing dumadi karo Cici iki beda klawan ing wektu awan. Nanging merga mesakake lan ora pengin gawe lara atine kancane, Kiki lan Koko mung ngempet"

Terjemahan :

"Mendengar ucapan Cici yang terlihat memelas itu, sesungguhnya Koko lan Kiki ingin tertawa. Karena apa yang terjadi dengan Cici sanagt berbeda dengan siang tadi. Tetapu karena kasihan dan tidak ingin membaut sakit hati temanya, Kiki dan Koko hanya menahan."

Pada kutipan itu diketahui jika Kiki dan Koko merupakan orang yang baik, dirinya tidak ingin mengolok-olok kekurangan temanya. Karena mereka tahu jika hal ini merupakan perbuatan yang buruk da tidak benar. Teman harus bisa saling menyayangi satu dengan lainya bukan malah saling menghina dan merendahkan kekuranganya.

Keteladanan juga nampak pada cerita anak berbahasa Jawa lainya, hal ini nampak pada kutipan berikut:

"Sasa banjur meneng lan mikir mesthi biaya nang dokter kewan kuwi larang. Durung tuku pasir lan pakane ya larang. Trus sing marakake kabotan yaiku kudu ngrumat dhewe. Esuk Sasa 
mesthi kudu tangi gasik, buwang kotoran, ngekeki pakan lan ngombe. Trus bali sekolah kudu ngecek pakane. Durung maneh seminggu pisan kudu ngedusi. Apa maneh nek nganti lara kudu digawa menyang dokter. Mikir kaya ngono Sasa banjur matur karo ibune nalika bali sekolah"

Terjemahan :

"Sasa kemudian diam dan berpikir pasti biaya ke dokter hewan itu mahal. Belum lagi beli pasir dan makanannya pasti mahal. Terus yang memberatkan adalah harus merawatnya sendiri. Pagi Sasa harus segera bangun membuang kotoran dan memberi makanan dan minum. Terus pulang sekolah harus memeriksa makanannya. Belum lagi seminggu sekali harus memandikannya. Apa lagi jika sakit harus dibawa ke dokter. Berpikir seperti itu Sasa kemudian mengatakan kepada ibunya pulang sekolah."

Pendidikan karakter keteladanan terlihat jelas pada pola pikir Sasa yang dewasa. Dia tidak menjadi anak yang egois mengedepankan dan mementingkan keingannya saja, tanpa memikirkna orang lain. Dia memikirkan segala hal yang akan terjadi dan biaya-biaya untuk merawat seekor kucing. Dengan banyaknya biaya dan banyaknya hal yang harus dilakukannya dalam merawat kucing, dia memilih untuk mengurungkan keinganannya memelihara kucing. Hal ini dilakukannya karena dia sudah tau jelas tidak sanggup merawatnya sendirian, dan berujung dengan merpeotkan ibunya mengurus kucing tersebut. Pola pikir Sasa yang dewasa inilah patut untuk ditiru oleh siapapun, tidak mementingkan dirinya sendiri.

"Enjang kula sekolah wangsul sekolah kadhang sampun kesel, dereng menawi wonten PR utawi ulangan kula mangke rak konsentrasi dhateng tugas sekolah, tartamtu kula ngliwakaken kucing. Ibu mesthi boten tegel kalih kucing wau, mesthi mawon ingkang ngupara ibu."

Terjemahan :

“Pagi saya sekolah pulang sekolah terkadang sudah capek, belum lagi jika ada PR atau ujian nanti saya harus fokus terhadap tugas sekolah, sudah tentu saya menelantarkan kucingnya. Ibu pasti tidak tega dengan kucing tadi, sudah pasti ibu yang melakukannya."

Pendidikan karakter keteladanan yang digambarkan pada kutipan di atas sangat menunjukkan jika Sasa sebagai anak yang teladan dalam urusan pendidikan. Dia benarbenar memperhitungkans segala kemungkinan kesibukannya karena kegiatan sekolah. Padahal jika diperhitungkan lagi mengurus kucing bukanlah hal yang membuang waktu banyak. Tetapi di sini Sasa benar-benar memperhitungkannya, karena dia tidak mau meninggalkan kewajibannya sebagai seorang pelajar. Layaknya seorang pelajar yang giat dalam hal pendidikan, dia sangat mengutamakan segala sesuatu yang berhubungan dengan kegiatan sekolahnya. Keteladanannya dalam belajar inilah patut untuk dijadikan teladan bagi semua pelajar, apapun kegiatan yang dilakukan jangan sampai mengesampingkang kegiatan sekolah.

Pada cerita ana "Joni Ora Mlebu Sekolah" ini juga terdapat nilai keteladanan, dibuktikan melalui kalimat berikut ini: 
"Nggih, Bu. Kula nyuwun pangapunten. Janji mboten badhe mbolos malih" Wangsulane Joni sinambi nyalami Bu Jar, Pak Joko, Ibuke, lan kanca-kancane.

Terjemahan :

"Ya, Bu. Saya meminta maaf. Janji tidak akan mengulangi untuk membolos sekolah lagi.". Ucap Joni sambil menyalami Bu Jar, Pak Joko, Ibunya, dan teman-temannya.

Bukti sikap keteladanan yang ada pada Joni ini sangatlah terlihat pada akhir cerita. Bahwa sebaiknya kita menggunakan waktu belajar ini sebaik mungkin. Kita boleh bermain asalkan ingat waktu. Jangan sampai lupa akan kewajiban kita. Demikian apa yang telah dilakukan oleh Joni, ia berjanji agar tidak mengulangi untuk membolos sekolah lagi.

"Nanging sakwise weruh perjuangane Udin esuk iki mau, Fais janji karo awake dhewe yen wiwit saiki dheweke arep ngrubah pakulinane sing ora becik kuwi. Dheweke bakal luwih ngati-ati lan nggunakake banyu saperlune wae. Aja nganti mbuwang-buwang banyu kanthi percumah."

Terjemahan :

"Akan tetapi setelah mengetahui perjuangannya Udin tadi pagi, Fais janji dengan dirinya sendiri bahwa mulai sekarang ia akan merubah tingkah lakunya yang tidak baik. Ia akan lebih berhatihati dan menggunakan air seperlunya saja. Jangan sampai membuangbuang air dengan percuma."

Kutipan data di atas menggambarkan sosok Fais terkagum dengan apa yang telah dilakukan Udin dalam mencari air. Udin mampu menjadi sosok teladan bagi Fais untuk merubah sikap buruknya selama ini. Dulu ketika dinasehati oleh kedua orang tuanya, Fais selalu menganggap seperti angin lewat. Akan teteapi, setelah mengetahui kisah perjuangan Udin ia menjadi sadar. Fais juga berjanji akan berubah menjadi lebih baik dan memanfaatkan air dengan seperlunya saja.

Secara tidak langsung Udin telah memberikan contoh teladan yang baik bagi Fais. Sehingga kisah perjuangannya mampu memberikan inspirasi untuk berubah ke hal yang lebih baik. Berdasarkan hal tersebut kutipan data di atas menjelaskan tentang nilai Integritas yaitu bab keteladan bagi seseorang, khsususnya pembaca.

Nilai keteladanan lainnya juga nampak pada cerita berikut:

Bapake kaget, banjur wanti-wanti, "Mbok menawa wae pancen wis nasibe kaya ngono. Nanging kedadean iki kudu dadi pelajaan kanggomu, No. Eling-elingen, daging ayam goreng sing wis ngiler yen dipangan pancen bisa mbebayani kanggo sapa wae, merga ana kuman-kumane sing bisa ngrusak sistem pencernaan."

Terjemahan :

Bapaknya kaget, kemudian mengingatkan "Mungkin saja sudah nasibnya seperti itu. Tapi kejadian ini harus menjadi pelajaran untukmu, No. Ingatlah bahwa daging ayam goreng yang sudah basi jika dimakan memang bisa membahayakan untuk siapa saja, karena sudah ada kuman-kuman yang bisa merusak sistem pencernaan." 
Dari kutipan tersebut dapat diketahui bahwa ayah Mano adalah sosok yang bisa ditiru untuk dijadikan teladan. Ayah Mano telah memberikan contoh yang baik untuk Mano, meskipun Mano sudah terlanjur melakukan perbuatan yang salah. Dari kutipan tersebut ayah Mano mengingatkan kepada Mano agar tidak membuang makanan daging ayam ke tempat sampah. Karena makanan yang sudah basi dapat menimbulkan bahaya untuk siapapun, didalamnya sudah terkandung kuman-kuman yang bisa merusak sitem pencernaan. Oleh kejadian itu, Ayah Mano mengingatkan kepada Mano untuk menjadikan hal tersebut sebagai pelajaran dan agar tidak mengulangi kembali kejadian tersebut

\section{Kesantunan}

Nilai integritas selanjutnya adalah nilai kesantunan. Berikut ini merupakan kutipan yang menunjukkan nilai kesantunan dalam wacan bocah berjudul "Ayo Nyepedhah".

“Assalamualaikum..." tibake petugas OSIS sing teka arep narik sumbangan sukarela.

(Panjebar Semangat No.15-11 April 2020, Kaca 46).

Terjemahan:

"Assalamualaikum..." ternyata petugas OSIS yang datang akan menarik sumbangan sukarela. (Panjebar Semangat No.15-11 April 2020, Halaman 46).

Berdasarkan cuplikan di atas dapat diketahui bahwa petugas OSIS yang berstatus sebagai siswa di sekolah tersebut menerapkan nilai kesantunan, yakni lewat pengucapan salam kepada guru yang berada di kelas. Sebuah tuturan yang baik haruslah memiliki pembuka. Pembuka dalam hal ini digunakan dengan tujuan sebagai bentuk penghormatan kepada guru. Bagian pembuka bisa dengan menggunakan kata salam pembuka, seperti permohonan maaf atau mengucapkan salam.

"Bu, Sasa mboten siyos kepengin ngingu kucing."

"Lho, lha kenangapa? Ibu mau wis pesen kancane ibu yen kepengin nyuwun kucinge siji."

"Mboten siyos mawon bu."

Terjemahan :

"Bu, Sasa tidak jadi ingin memelihara kucing."

"Lho kenapa? Ibu terlanjur pesan sama temennya ibu minta kucingnya satu."

“Tidak jadi saja bu."

Pada kutipan di atas pendidikan karakter kesantunan ditunjukkan oleh Sasa melalui perkatannya kepada ibunya. Meskipun orang diajak berbicara adalah ibunya sendiri, tetapi bahasa yang digunakan tetaplah santun. Dalam berbicarapun kepada ibunya Sasa juga beretika. Padahal apa yang dikatakan Saasa kepada ibunya membuatnya sedih, tetapi hal ini tidak membuatnya lantas meluapkan emosinya atau berkata kasar. Sebagai seorang anak yang berbakti kepada orangtua, kesantunan Sasa kepada ibunya menjunjukkan dia anak yang mengerti sopan santun. 
Kesantunan juga dapat dimaknai sebagai sebuah kalimat dalam berbahasa yang dapat dilakukan dengan cara pelaku untuk mematuhi prinsip sopan santun dalam berbahasa yang berlaku. Seperti yang ada dalam cerita anak "kancil pilek". Kesantunan tersebut terdapat pada kutipan data berikut:

"piye kebo? Kedhatonku iku piye kahanane?" pitakone macan

"Matur jujur lho nggih?"

"Iya."

"wah... kedhaton panjenengan menika ambetipun kok pesing tur badheg menika persisi kendhang kewan."

"piye?"

"ambetipun mboten ngiyati. Kula meh mutah kalawau!"

Terjemahan :

“bagaimana kebo? Rumahku ini bagaimana keadaannya?" pertanyaan Macan

"bicara jujur lho ya?"

"Iyа."

"Wah... rumahmu ini baunya pesing dan tidak enak ini sama dengan kndhang hewan"

"bagaimana?"

"baunya tidak kuat, saya tadi hampir mau muntah!"

Pada kutipan data tersebut menjelaskan bahwa diterapkannya kesantunan dalam berbicara. Kebo tersebut menggunakan kesantunan karena yang berbicara dengan kebo adalah Raja hutan. Kebo harus menghormati si Macan tersebut, meskipun Si macan tersebut memiliki sikap seenaknya sendiri. kesantunan Bahasa ini merupakan bentuk pendidikan karakter integritas yang cocok untuk digunakan dalam pendidikan karakter anak-anak. Apalagi sekarang banyak anak muda yang lupa akan kesantunan untuk berbicara, berperilaku, dan juga dalam bertindak. dengan adanya kesantunan dalam cerita anak ini dapat memberikan gambaran atau contoh untuk menerapkan sebuah kesantunan dalam berbahasa.

Ketika kancil dipanggil oleh Macan untuk melihat tempat tinggal Raja yaitu Macan. Kancil menggunakan kesantunan dalam berbicara meskipun Kancil telah berbohong untuk menyelamatkan dirinya dari si Macan, karena Kancil tidak mau nasibnya sama dengan hewan-hewan yang lain. Kutipan data tersebut terdapat pada:

"Kancil? Saiki kowe kandha jujur wae; piye kahanane kedhatonku iki? Pitakone Macan.

"Aduh! Nyuwun pangapunten Sang Raja, kula sak niki nembe pilek. Kula mboten saged ngambet kiwa tengen. Mripat kula nggih rembes. Mboten saged nyawang kahanan kanthi gamblang. Kula mboten saged matur Kangjeng!"

"Kowe ora ngapusi?" 
"mboten Sang Raja. Cobi paduka priksani; niki irung kula meler," kandhane karo ngetokake umbel saka irunge. Sakala Macan percaya karo kandhane Si kancil.

Terjemahan :

"kancil? Sekarang kamu bicara jujur saja; bagaimana keadaan rumahku ini?" pertanyaan Macan.

"aduh! Saya minta maaf Sang Raja, saya sekarang lagi pilek. Saya tidak bisa mencium bau kiri kanan saya. Mata saya juga banyak keteknya. Tidak bisa melihat keadaan dengan jelas. Saya tidak bisa berbicara Kangjeng!"

"kamu tidak berbohong?"

“tidak sang Raja. Coba Raja priksa; ini hidung saya mbeler." Menjelaskan dengan mengeluarkan umbel dari hidungnya. Seketika Macan percaya dengan apa yang dijelaskan Si Kancil.

Pada kutipan data tersebut digambarkan penerapan kesantunan dalam berbicara. Kancil tersebut menggunakan bahasa yang santun karena yang berbicara denganRaja hutan. Jadi Kancil harus menghormati si Macan tersebut, meskipun Si macan tersebut memiliki sikap seenaknya sendiri.

Dalam cerita "Joni Ora Mlebu Sekolah" terdapat penanaman sikap kesantunan. Kesantunan dapat didefinisikan sebagai sikap yang berperilaku dengan pantas, tidak hanya dari berbahasa namun juga berperilaku non-verbal. Sikap kesantunan ini merupakan titik pertemuan antara bahasa dan realitas sosial. Sikap kesantunan pada cerita "Joni Ora Mlebu Sekolah" ini dibuktikan melalui kutipan dialog berikut ini :

"Kinten-kinten dhateng Pundi,nggih ? Napa wonten masalah kalih Joni,Bu?" Bu Jar nlesih alon-alon. Ibuke Joni ngandhakake yen ora ana apa-apa. Kabeh lumaku apik kaya padatane.

Terjemahan :

“Kira-kira kemana ya? Apakah sedang ada masalah dengan Joni,Bu?" Bu Jar menanyakan dengan pelan. Ibunya Joni memberitahukan bahwa sedang tidak terjadi masalah apaapa. Semuanya berjalan dengan baik seperti biasanya.

Tampak jelas bahwa yang dikatakan oleh $\mathrm{Bu}$ Jar ini memberikan kesan santun meskipun pada saat itu suasana sedang genting. Tokoh Bu Jar menanyakan kepada Joni, dan akhirnya memang menurut Ibunya, Joni juga tidak sedang terjadi masalah apa-apa pada saat di rumah. Kemudian setelah semua teman-teman ditanyai mengenai permasalahan apa yang terjadi, dan memang tidak ada akhirnyapun $\mathrm{Bu}$ Jar bergegas meminta pamit pada saat itu. Hal ini juga dilakukan dengan baik-baik agar tidak menyinggung hatinya Ibunya Joni. Berikut ini kutipan dialognya :

Bareng dirasa wis cukup, Bu Jar lan bocah-bocah banjur nyuwun pamit. Bu Jar uga ninggal weling yen Joni wis mulih ora perlu diseneni. Cukup ditakoni apa alesane ora mlebu sekolah. 
Terjemahan :

Setelah semuanya dirasa cukup, Bu Jar dan anak-anak kemudia berpamitan. Bu Jar juga meninggalkan pesan jika Joni sudah pulang tidak perlu dimarahi. Cukup ditanya apa alasannya tidak masuk sekolah.

Hal di atas menunjukkan bahwa adanya bukti sikap keantunan yang diperagakan oleh tokoh Bu Jar ketika memberitahu kepada Ibunya Joni agar tidak memarahi anaknya ketika nanti sudah pulang ke rumah. Tanpa rasa marah, tanpa rasa curiga $\mathrm{Bu}$ Jar memberikan saran itu semata-mata untuk kebaikan Joni pula. Tidak lama kemudian, Joni datang dengan keadaan yang sangat takut karena banyak temannya yang datang ke rumah. Hal ini menjadikan Joni untuk diam diri dan tidak berani mengatakan apa-apa. Sikap diam Joni ini juga sebenarnya menunjukkan suatu sikap kesantunannya tanpa disengaja. Hal ini dinuktikan melalui kutipan berikut ini:

Joni meneng sauntara. Ndhingkluk ora wani nyawang sapa-sapa. Dheweke wedi yen mengkone bakal diseneni gurune lan wong tuwane. Kancan-kancane mesthine uga padha pegel. Joni Wedi yen nganti ora nduwe kanca ing sekolah.

Terjemahan :

Joni diam sebentar. Dia menundukkan kepala dan tidak berani melihat siapapun. Dia takut jika nanti dia dimarahi oleh guru dan orang tuanya. Teman-temannya juga semestinya merasa capek (atas perbuatannya). Joni takut jika dia tidak memiliki teman saat berada di sekolah.

Bukti kalimat tersebut menunjukkan bahwa meskipun Joni sedang mengalami masalah, ia tidak lupa akan sikap kesantunan yang ia lakukan. Dengan cara menundukkan kepala ia menjadikannya sebagai wujud hormat kepada semua orang yang ada di sana, yang telah ke rumah Joni dengan tujuan mengetahui bagaimana keberadaan si Joni. Selain itu Joni juga takut jika apa yang telah ia lakukan pada saat itu menjadi hal yang membuat temannya menjauhinya dan ia takut jika tidak memiliki teman ketika di sekolah.

"Leren, sik. Iki lho, sarapane wis mateng," ujare ibune sing lagi nyaponi latar nalika weruh tekane Udin lan bapake.

"Nggih. Niki lho, takngedhunke jrigen riyen," saurane Udin karo uwat-uwet nguculi tali sing dienggo nggubet jrigen nang dhuwur goncengan sepedha.

Terjemahan :

"Berhenti, dulu. Ini loh, sarapannya sudah matang," ujar Ibu yang sedang menyapu halaman ketika mengetahui datangnya Udin dan ayahnya.

"Iya. Ini loh, saya mau menurunkan jerigen dulu," Udin menjawab sambil melepas tali yang digunakan untuk menali jerigen di atas boncengan sepeda.

Dari kutipan di atas dijelaskan bahwa sosok Udin sangat santun dan hormat kepada sang Ibu. Hal tersebut dibuktikan dengan cara ia menjawab pernyataan sang Ibu yaitu dengan Bahasa Jawa Krama. Bahasa Jawa krama biasanya digunakan untuk berbicara kepada 
orang yang lebih tua atau orang yang pantas untuk dihormati. Begitupun yang dilakukan oleh Udin, ia menghormati dan tunduk kepada Ibunya dengan cara berbicara yang sopan, santun dan halus menggunakan bahasa Jawa krama tersebut. Berdasarkan pernyataan tersebut nilai pendidikan karakter integritas ada pada cerita anak di atas, yaitu nilai kesantunan.

\section{Cinta pada Kebenaran}

Cinta kepada kebenaran sendiri didefinisikan sebagai suatu hal yang merujuk kepada cinta kepada hal-hal yang baik dan tidak mengandung unsur kebohongan. Mengenai cinta kebenaran ini dibuktikan melalui kutipan data berikut :

"Sampun tigang dinten niki Joni mboten masuk. Menapa sakit,Bu?" pitakone bu Jar. "Menapa mboten sekolah? Saben enjing pamite nggih bidhal sekolah", wangsulane Ibuke Joni tambang bingung lan wedi, pungkasane nangis.

Terjemahan :

"Sudah tiga hari ini Joni tidak masuk. Apaka sakit,Bu?" tanya Bu Jar. "Apakah tida sekolah? Setiap pagi pamitnya ya berangkat sekolah", jawab Ibunya Joni dengan perasaan yang bingung dan takut, hingga akhirnya menangis.

Setelah membaca kutipan dialog yang diakukan oleh Ibunya Joni dan Bu Jar kita dapat mengatakan bahwa Ibu Jar ini memiliki watak yang suka akan sebuah kebenaran. Bu Jar akhirnya bertanya kepada Ibunya Joni apa yang sebenarnya terjadi pada Joni. Kemudian tidak sengaja, karena memang pada saat itu Ibunya Joni sedang bingung kenapa anaknya tidak masuk sekolah dan apa yang menyebabkannya ia tidak masuk sekolah pada saat itu. Tanpa disadari akhirnya Ibunya Jonipun meneteskan air matanya.

Pengertian lain dari cinta kepada kebenaran yaitu suka dan menerima dengan kebenaran yang ada. Dalam wacan bocah yang berjudul "Oplas" terdapat salah satu nilai pendidikan karakter yaitu cinta kepada kebenaran, berikut bukti kutipan dalam wacan bocah;

"Oplas" sing dikira obat ora ana gunane, lan dianggep mung solasi saiki dheweke ngerti gunane.

Terjemahan :

"Oplas" yang dikira obat yang tidak ada gunanya, dan dianggap hanya selotip sekarang dia mengerti fungsinya.

Dari kutipan di atas bisa dilihat, jika terdapat nilai pendidikan karakter berupa cinta kepada kebenaran. Sikap cinta kepada kebenaran ditunjukkan oleh tokoh Sari, yang pertama mengira obat "oplas" tersebut tidak ada gunanya, ternyata memiliki kegunaan yang sama pentingnya. Kebenaran dari kegunaan obat "oplas" diterima oleh tokoh Sari dengan perasaan senang. Sebab pengetahuannya sekarang bertambah mengenai kegunaan obat "oplas". Tokoh Sari menerima kebenaran yang ada tersebut, juga disebabkan dia melihat secara langsung kegunaan obat tersebut. Sikap yang ditunjukkan oleh tokoh Sari juga termasuk dalam nilai pendidikan karakter yaitu cinta kepada kebenaran. Sikap cinta kepada 
kebenaran harus ditumbuhkan sejak usia anak-anak. Hal tersebut bertujuan agar kelak anak-anak bisa menerima kebenaran akan sesuatu hal yang ada dan kebenaran tersebut bisa menambah pengetahuan dan pengalaman.

Perilaku cinta terhadap kebenaran merupakan sebuah sikap yang harus kita tumbuh kembangkan dalam kehidupan sehari-hari. Cinta pada kebenaran dapat diartikan sebagai perilaku mendukung adanya kebenaran yang telah disampaikan. Kebenaran merupakan sebuah fakta yang senantiasa akan memberikan kebaikan kepada orang-orang yang mendukung kebenaran tersebut. Dalam bacaan anak “Wong Pepriman kang Jujur" perilaku cinta kebenaran diterapkan oleh Pak Hakim. Dapat dilihat melalui kutipan berikut ini:

"Tuan sudagar, kowe kandha tas kulitmu kang ilang isine rong atus dhuwit emas.

Dene, wong ngemis iki ngandhakake yen dheweke nemokake tas kulit kang isine mung satus dhuwit koin emas. Yen ngono ateges tas iki dudu duwekmu. Mula saiki, balekna tas kuwi menyang wong ngemis kuwi. Ya wong ngemis kuwi kang duweni tas kasebut..."

Terjemahan :

“Tuan saudagar, anda bilang kalau tas kulit anda isinya duaratus duwit emas. Sedangkan pengemis ini bilang kalau dia menemukan tas isinya seratus duwit koin emas. Itu berarti tas tersebut bukan milik anda. Maka dari itu, sekarang kembalikan tas itu pada pengemis tersebut. Ya si pengemis tadi pemilik tas tersebut.."

Perilaku cinta kebenaran di atas dicerminkan oleh Pak Hakim. Pak Hakim melihat kejujuran dari si pengemis tadi. Maka dari itu Pak Hakim mendukung kebenaran yang dilakukan oleh si pengemis tersebut. Kebenaran senantiasa akan membawa dampak baik pada diri kita. Sedangkan kebohongan akan memberikan dampak yang buruk dari diri kita. Sesuai bacaan tersebut dapat dilihat bahwa si pengemis menuai hasil baik atas perbuatan baiknya, sedangkan si saudagar kaya menuai dampak dari perbuatan yang dilakukannya.

\section{PENUTUP}

\section{Simpulan}

Berdasarkan analisis analisis terhadap teks sastra anak wacan bocah dalam panjebar semangat, ditemukan empat jenis pendidikan karakter integritas. Empat jenis pendidikan karakter integritas, yaitu; 1) kejujuran, 2) keteladanan, 3) kesantunan, dan 4) cinta pada kebenaran. Keempat pendidikan karakter tersebut digambarkan baik secara implisit maupun eksplisit dalam wacan bocah oleh pengarang.

\section{Saran}

Berdasarkan kebutuhan warisan sastra terhadap anak-anak, serta kepentingan penanaman karakter sejak usia dini, diperlukan banyak pihak yag terlibat. Pihak-pihak tersebut antara lain: Pengarang sebagai sumber bacaan untuk tetap mencipta karya-karya 
sastra untuk anak-anak, Guru sebagai pendidik dapat menggunakan teks sastra anak untuk penanaman karakter, Orang tua juga membiasakan anak-anak untuk membaca dan menyimak cerita-cerita anak bermuatan pendidikan karakter.

\section{E. DAFTAR PUSTAKA}

Galda, Lee, Ash, G. E., \& Cullinan, B. E. “Research on Children's Literature,” 2001.

Muchlas Samani dan Hariyanto. Pendidikan Karakter. Bandung: Rosdakarya, 2011.

Neina, Qurrota Ayu. "Dongeng Abad 21: Modernisasi Sastra Anak Berbasis Psikologi Perkembangan." Jurnal Sastra Indonesia 7, no. 3 (2019): 202-11. https://doi.org/10.15294/jsi.v7i3.29846.

Rumidjan. Dasar Keilmuan dan Pembelajaran Sastra Anak SD. FIP UM, 2013.

Sarumpaet, Riris K. Toha. Pedoman Penelitian Sastra Anak. Yayasan Pustaka Obor Indonesia, 2010.

Sugiarti. "Kajian Sastra Anak " Kecil-Kecil Punya Karya The Evergreen " Karya Nisrina Hanifah dalam Perspektif Pendidikan Karakter." Jurnal Humanity 8, no. 2 (2013): 94105.

http://ejournal.umm.ac.id/index.php/humanity/article/view/2103.

Winarni, Retno. Kajian Sastra Anak. Yogyakarta: Graha Ilmu, 2014.

Zubaedi. Desain Pendidikan Karakter. Jakarta: Kencana Prenada Media Group, 2013. 